\title{
Magnetic Force Microscopy of the Ethmoid Bones of Migratory and Non-Migratory Fishes
}

\author{
S. Gorobets ${ }^{a}$, O. Gorobets $^{a}$, M. Bulaievska ${ }^{a, *}$ And I. Sharau ${ }^{b}$ \\ ${ }^{a}$ Igor Sikorsky Kyiv Polytechnic Institute, 03056 Kyiv, Ukraine \\ ${ }^{b}$ Institute of Magnetism NAS of Ukraine and MESYS of Ukraine, 03142 Kyiv, Ukraine
}

\begin{abstract}
For a long time it was believed that the biogenic magnetic nanoparticles (BMNs) in the ethmoid bones of fishes and birds are associated with navigation in the geomagnetic field. However, it was proven that BMNs don't affect the ability of migratory birds to orient in the Earth's magnetic field. It is relevant to check the presence of BMNs in organs of migratory and non-migratory fishes. The presence of BMNs was investigated in the samples of ethmoid bones of atlantic salmon, northern pike and silver carp by the method of magnetic force microscopy. As a result, the biological material of ethmoid bones of migratory and non-migratory fishes contain both separate BMNs and their chains, so BMNs in the ethmoid bone of fishes are not related to their ability to migrate in the geomagnetic field.
\end{abstract}

DOI: 10.12693/APhysPolA.133.734

PACS/topics: 81.05.- -t

\section{Introduction}

In 1975, Blackmore discovered the magnetotactic bacteria (MTB), which today are the most studied biomagnetic systems. Blackmore showed that these bacteria contain chains of crystal-like iron-containing nanoparticles, through which MTB move along magnetic field lines [1].

To date, biogenic magnetic nanoparticles (BMNs) have been detected in representatives of all three subkingdoms of living organisms: the Prokaryotes, the Archaea and the Eukaryotes, and a single biomineralization mechanism for all living organisms has been established [2]. Most phylogenetic groups of animals belonging to the kingdom of multicellular eukaryotic organisms are capable of biomineralization of BMNs, in particular insects [3], mollusks [4], fishes [5], amphibians and reptiles [6], birds [7] and mammals [8]. Magnetosensitive inclusions in the form of BMNs are found, for example, in sensory organs of the bat [9], in antennae of ants [3] and in the olfactory epithelium of trout [5].

The presence of BMNs was studied mainly from the point of view of the orientation of organisms in the external magnetic field of the Earth. The idea of magnetotaxis was very progressive and contributed to the fact that intensive research of this phenomenon in various microorganisms began in many scientific centers of the world. After BMNs were found in multicellular organisms [7, 8], the idea of magnetotaxis, as their main function, was transformed into the idea of the important role of BMNs in magnetoreception. The idea of magnetoreception was deeply studied and continues to be studied, but no unequivocal experimental confirmation was found, even in

*corresponding author; e-mail: marina_gromnadskaya@mail.ua the study of the orientation of migratory birds in the geomagnetic field [10].

At the moment, there is a lot of scattered data about the presence of BMNs in various organs of migratory fishes, but the overwhelming majority of studies are also aimed at confirming the idea of magnetoreception. Therefore, in particular, organs such as the ethmoid bone, the lateral line, and the brain have been studied $[11,12]$.

Therefore, to date, it is important to study the ethmoid bones of non-migratory fishes, to establish the presence of BMNs in them. Studies of nanostructural localization of BMNs will provide an opportunity to predict their functions in the ethmoid bone of animals.

The purpose of this study is to determine the localization of BMNs and their morphological characteristics in the ethmoid bone of non-migratory fishes.

\section{Material and equipment}

The proteome of migratory and non-migratory fishes was aligned with Magnetospirillum gryphiswaldense MSR-1 proteome using comparative genomics methods, the BMNs biomineralization mechanism in which has been studied in detail $[13,14]$. Most of the proteins that are involved in the biomineralization of BMNs in MTB are encoded in the magnetosome island (MAI) and is a manifestation of the genes of the magnetosome island $[14,15]$. The proteins MamA, MamB, MamM, MamE, MamO belong to proteins, without which the process of biomineralization of BMNs in MTB is impossible. Other proteins of the MTB MAI belong to regulatory proteins that are responsible for the control of shape, size, amount of BMNs in the cell, the formation of magnetosomal vesicles, and the formation of chains of BMNs [16]. MAI protein MamK is responsible for the formation of chains of BMNs in the MTB. 
Pairwise alignment methods were applied using the BLAST program of the National Center for Biotechnological Information for estimation of the degree of similarity between BMN biomineralization proteins of MTB Magnetospirillum gryphiswaldense MSR-1 and proteins of migratory and non-migratory fishes. The following statistical criteria were taken into account for estimation of the degree of similarity of aligned sequences. Ident is the number of identical amino acid residues of proteins, compared, with optimal alignment. E-number is the number reflecting the statistical significance of the alignment. A decrease of its value indicates a lower level of the occurrence of the randomness when the amino acid residues of the proteins coincide. Length is the length of the alignment. The alignment length should be greater than 100 amino acid residues and the function of the proteins should be examined [17].

Studies of the biological material of the ethmoid bones of migratory and non-migratory fishes were carried out using atomic force microscopy (AFM) and magnetic force microscopy (MFM). The magnetic probe MFM_LM series with chip size $3.4 \times 1.6 \times 0.3 \mathrm{~mm}$, coated by $\overline{\mathrm{CoCr}}$ was used. This probe was used both for AFM and MFM imaging. The non-contact AFM (NC-AFM) mode was applied. The MFM scanning was carried out at constant distance from the sample surface after AFM scanning. The probe "lift" height was $100 \mathrm{~nm}$. The cantilever was calibrated using the test samples. Calibration of the probe was carried out immediately before the measurements.

The biological material of the ethmoid bone of atlantic salmon, northern pike and silver carp was chosen as the object of investigation (Table I). The following preparation of ethmoid bones of migratory and non-migratory fishes was conducted before AFM and MFM scanning. Fixation of bone tissue was carried out with a $10 \%$ formalin solution for 24 hours. After that washing of the samples with distilled water and wiring through alcohols with increasing concentration (from $50 \%$ to $100 \%$ ) was done. Decalcification of bone tissue was carried out with $5 \%$ aqueous solution of nitric acid, duration of decalcification was equal to 24 hours. The next stage was rinse for 24 hours with $70 \%$ ethyl alcohol and filling the decalcified bones with liquid paraffin at a temperature of $55^{\circ} \mathrm{C}$. Solidification of paraffin was carried out at room temperature. The microtome was used for production of a slice of thickness 5 microns from a paraffin block. The slices were placed on a slide. Then the slices were released from the mounting medium.

\section{Results and discussion}

Today, there is no complete genomes of fishes in the databases. Since the magnetosome island could be out of the decoded region of the genome, the genetic analysis must be confirmed by comparing the functions of homologous proteins. However, the presence of BMNs in migratory fishes such as atlantic salmon, sockeye salmon,
TABLE I

The studied migratory and non-migratory fishes.

\begin{tabular}{c|c}
\hline \hline $\begin{array}{c}\text { Attitude to } \\
\text { migration }\end{array}$ & Investigated organisms \\
\hline Migratory & Atlantic salmon, Salmo salar \\
\hline Non-migratory & $\begin{array}{c}\text { Northern pike, Esox lucius } \\
\text { Eurp, Hypophthalmichthys molitrix } \\
\text { European carp, Cyprinus carpio }\end{array}$
\end{tabular}

yellowfin tuna and european eel has been proved experimentally $[11,12,18]$.

The alignment of MamA, MamB, MamM, MamE, MamO and MamK proteins of the MTB, without which biomineralization of BMNs is impossible, and the proteins of migratory and non-migratory fishes are shown in Table II.

TABLE II

Alignment of the amino acid sequences of a proteins of the MTB MAI of Magnetospirillum gryphiswaldense MSR-1 and the amino acid sequences of a proteins of migratory and non-migratory fishes.

\begin{tabular}{c|c|c|c|c|c|c}
\hline \hline \multirow{2}{*}{ Fish } & \multicolumn{5}{|c}{ M. gryphiswaldense MSR-1 proteins } \\
\cline { 2 - 7 } & \multicolumn{5}{|c}{ E-number/ident. [\%]/length } \\
\cline { 2 - 7 } Salmo & 0.023 & $2 \mathrm{e}-08$ & $9 \mathrm{e}-07$ & $1 \mathrm{e}-08$ & $1 \mathrm{e}-29$ & $4 \mathrm{e}-05$ \\
salar & $31 \%$ & $30 \%$ & $29 \%$ & $27 \%$ & $41 \%$ & $23 \%$ \\
& 59 & 107 & 114 & 177 & 171 & 172 \\
\hline \multirow{2}{*}{ Cyprinus } & $2 \mathrm{e}-05$ & $3 \mathrm{e}-11$ & $5 \mathrm{e}-07$ & 0.018 & $5 \mathrm{e}-16$ & $5 \mathrm{e}-05$ \\
carpio & $22 \%$ & $22 \%$ & $28 \%$ & $28 \%$ & $42 \%$ & $23 \%$ \\
& 153 & 270 & 114 & 96 & 139 & 175 \\
\hline \multirow{2}{*}{ Esox } & $2 \mathrm{e}-05$ & $1 \mathrm{e}-05$ & $5 \mathrm{e}-07$ & $8 \mathrm{e}-09$ & $6 \mathrm{e}-28$ & $2 \mathrm{e}-04$ \\
lucius & $28 \%$ & $28 \%$ & $29 \%$ & $27 \%$ & $42 \%$ & $29 \%$ \\
& 114 & 101 & 114 & 143 & 168 & 174
\end{tabular}

Thus, according to the results of the studies, it can be concluded that such organisms as atlantic salmon, european carp and northern pike are potential producers of BMNs. The homology of proteins is confirmed not only by the E-number, the number of identical amino acid residues of proteins (Ident) and the length of the alignment (Length), but also by the common functions of homologous proteins. The functions of the proteins MamA, MamB, MamM and MamE are similar to the functions of homologous fish proteins, which confirms the validity of bioinformatic analysis. At the same time, the presence of homologs of the MamK protein in all studied organisms suggests the possible formation of chains of BMNs by these organisms, which is confirmed by the results of scanning probe microscopy. Also, the presence of homologs of the MamK protein in all studied organisms may indicate the association of BMNs of these organisms with the cell membrane.

Samples of biological material of atlantic salmon, northern pike and silver carp were examined using a "Solver PRO-M" scanning probe microscope. The study 
was carried out using the methods of AFM and MFM. The image of the MFM reflects the spatial distribution of BMNs in the biological material of the ethmoid bones of migratory and non-migratory fishes, which are represented by black and white dots on MFM images. The results of the study of ethmoid bones of migratory and non-migratory fishes using scanning probe microscopy are shown in Fig. 1.

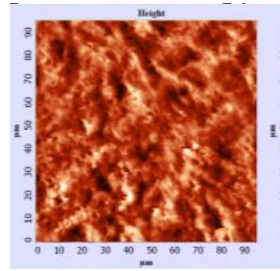

(a)

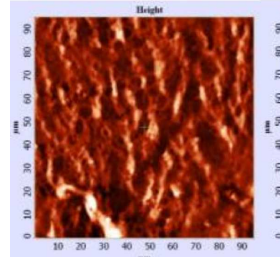

(d)

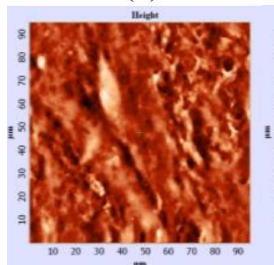

(g)

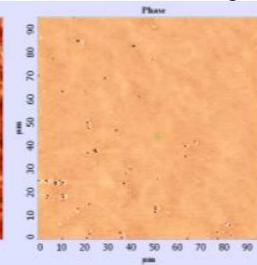

(b)

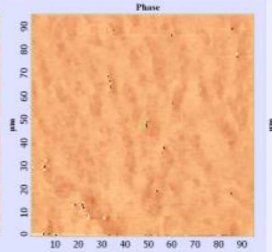

(e)

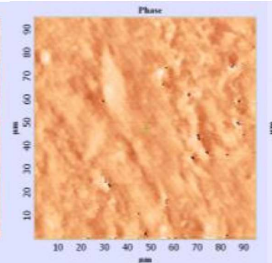

(h)

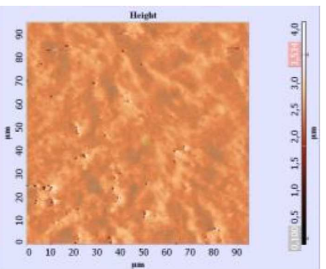

(c)

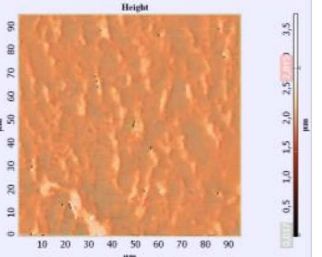

(f)

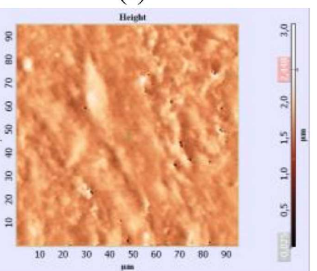

(i)
Fig. 1. Images of atlantic salmon ethmoid bone: (a) AFM image, (b) MFM image, (c) combined AFM and MFM images; images of northern pike ethmoid bone: (d) AFM image, (e) MFM image, (f) combined AFM and MFM images; images of silver carp ethmoid bone: (g) AFM image, (h) MFM image, (i) combined $\mathrm{AFM}$ and MFM images.

The dark "spikes" (Fig. 1) are obtained only as a result of MFM scanning and don't arise at AFM scanning of the sample surface topography. The repeating of MFM scanning several times in different (perpendicular) directions of scanning don't change the spatial distribution of "spikes". It proves that the "spikes" characterize the presence of magnetic nanoparticles. The figures 1c, 1f, 1e represent the overlapping of AFM topography image with MFM image. It means that MFM and AFM images were combines in one image (using Adobe Photoshop CS5) with the purpose of revealing peculiarities of topography of the surface in the vicinity of BMNs. As can be seen from Fig. 1, the atlantic salmon ethmoid bone contains BMN. In the MFM image, there are many regions where single BMN and their chains are detected. The number of BMN in the silver carp ethmoid bone is slightly higher than the number of BMN in the northern pike ethmoid bone and is slightly less than the number of BMN in the atlantic salmon ethmoid bone. BMNs in the ethmoid bones of the silver carp and northern pike are localized mostly separately or assembled into short chains. Table III gives the following characteristics of BMNs: density and quantity in the chain.

TABLE III

Number of BMNs in the ethmoid bones of migratory and non-migratory fishes.

\begin{tabular}{c|c|c}
\hline \hline Fish under study & $\begin{array}{c}\text { Number } \\
\text { of particles } \\
\text { per } 100 \mu \mathrm{m}^{2}\end{array}$ & $\begin{array}{c}\text { Av. number } \\
\text { of particles } \\
\text { in chain }\end{array}$ \\
\hline Atlantic salmon & $150 \pm 19$ & $7 \pm 1$ \\
Northern pike & $57 \pm 3$ & $6 \pm 1$ \\
Silver carp & $86 \pm 16$ & $5 \pm 1$
\end{tabular}

\section{Conclusions}

The carried out bioinformation analysis showed that the following organisms are potential producers of BMNs: atlantic salmon (Salmo salar), european carp (Cyprinus carpio) and northern pike (Esox lucius).

As a result of the conducted studies with the help of scanning probe microscopy, it was established that BMNs are found in the ethmoid bones of migratory fishes (atlantic salmon) and non-migratory fishes (northern pike and silver carp). The number of BMNs in the ethmoid bone of the atlantic salmon is somewhat higher than in the ethmoid bones of the silver carp and the northern pike. BMNs in the samples are diffusely distributed, clustering into small clusters, and also forming chains.

For the first time it has been revealed that in the ethmoid bone of non-migratory fishes, namely: northern pike and silver carp, existing magnetosensitive structures of endogenous origin in the form of a set of separate localized nanosized elements. The results indicate that BMNs in the ethmoid bone of migratory and nonmigratory fishes are most likely to be separators for trapping efficiently paramagnetic clusters. That is, BMNs in the ethmoid bone of fishes are not involved in the orientation of animals in the external magnetic field of the Earth.

\section{Acknowledgments}

This project has received funding from the European Union Horizon 2020 research and innovation programme under the Marie Skłodowska-Curie grant agreement No 644348 (MagIC).

\section{References}

[1] A. Komeili, FEMS Microbiol Rev. 36, 232 (2012).

[2] O. Gorobets, S. Gorobets, Yu. Gorobets, Dekker Encyclopedia of Nanoscience and Nanotechnology. 3, 300 (2014)

[3] J.F. de Oliveira, E. Wajnberg, D.M. Esquivel, S. Weinkauf, M. Winklhofer, M. Hanzlik, J. R. Soc. Interface. 7, 143 (2010). 
[4] L. M. Gordon, D. Joester, Nature 194, 469 (2011).

[5] S. Eder, H. Cadiou, A. Muhamad, P. McNaughton, PNAS 109, 12022 (2012).

[6] A. Perry, G.B. Bauer, A.E. Dizon, Plenum Press. 5, 439 (1985).

[7] C. Walcott, J. L. Gould, J. L. Kirschvink, Science 205, 1027 (1979).

[8] J. Zoeger, J. Dunn, M. Fuller, Science. 213, 892 (1981).

[9] R. Holland, J. Kirschvink, T. Doak, M. Wikelski, PLoS ONE. 3, e1676 (2008).

[10] T. Ritz, P. Thalau, J.B. Phillips, Nature. 429, 177 (2004).

[11] M.M. Walker, T.P. Quinn, J.L. Kirschvink, C. Groot, J. Exp. Biol. 140, 51 (1998).
[12] M. Walker, J. Kirschvink, S.-B. Chang, A. Dizon, Science 224, 751 (1984).

[13] S. Ullrich, M. Kube, S. Schübbe, J. Bacteriol. 187, 7176 (2005).

[14] S. Schubbe, Ch.Wurdemann, J. Peplies, U. Heyen, C. Wawer, F. Glockner, D. Schuler, Appl. Environment. Microbiol. 72, 5757 (2006).

[15] M. Richter, M. Kube, D. A. Bazylinski, J. Bacteriol. 189, 4899 (2007).

[16] A. Lohße, PLoS ONE. 6, e25561 (2011).

[17] W. Li, F. Pio, K. Pawłowski, Bioinformatics. 16 , 1105 (2000)

[18] A. Moore, S. Freake, I. Thomas, Philos. Trans. $R$. Soc. London B. 329, 11 (1990). 